\title{
PEMANFAATAN BUAH EDIBEL OLEH SUKU DAYAK BAKATI DI HUTAN TEMBAWANG DESA TIRTA KENCANA KECAMATAN BENGKAYANG KABUPATEN BENGKAYANG
}

\author{
Anggi Wibowo ${ }^{1}$, Rafdinal ${ }^{1}$, Siti Ifadatin ${ }^{1}$ \\ ${ }^{1}$ Program Studi Biologi, Fakultas MIPA, Universitas Tanjungpura, \\ JL. Prof. Dr. H. Hadari Nawawi, Pontianak, 78124 \\ email korespondensi : anggianggiwibowo1@gmail.com
}

\begin{abstract}
The Dayaknese people of Bakati in Tirta Kencana Village at Bengkayang District of Bengkayang Regency have a Tembawang forest that planted with edibel forest fruits. This study aims to determine the types of edible fruits that have been consumed by residents of Tirta Kencana Village at Bengkayang District of Bengkayang Regency. This research has been carried out for two months from April 2019 to May 2019. This research was used a survey and interview methods. Edibel fruit found in the Tembawang forest that consists of 21 which belong to 14 families. The part of the fruit that is eaten in the flesh of the seed coat. The use of edible fruit by the local population is still relatively simple, which is either eaten directly, cooked, processed by fermentation, processed into candied snacks and cooking spices.
\end{abstract}

Keywords : edible fruit, Tembawang forest, Dayak Bakati, Tirta Kencana Village

\section{PENDAHULUAN}

Buah-buahan hutan di Kalimantan Barat banyak dijumpai di hutan tembawang yang digunakan oleh suku Dayak. Tembawang merupakan suatu lahan bekas ladang dan rumah panjang yang secara sengaja/tidak sengaja ditanami biji-bijian oleh nenek moyang kemudian ditinggalkan karena suatu kejadian (De Forest et al., 2000).

Tembawang merupakan sistem agroforestri kompleks yang terdiri dari sejumlah besar unsur pepohonan, perdu, tanaman musiman dan atau rumput (De Foresta et al., 2000). Penampakan fisik dan dinamika di dalamnya mirip dengan ekosistem hutan alam primer maupun sekunder. Tembawang diwariskan secara turun temurun dari nenek moyang bisa secara kolektif berdasarkan garis keturunan ataupun perseorangan/keluarga serta adat (Sardana et al., 2011). Sumber daya penting dalam kawasan tembawang bukan tanah, namun pepohonan yang ada di dalamnya. Individu, keluarga, atau kelompok seketurunan dapat memegang, mewarisi atau mentransfer hak atau akses ke tumbuhan tertentu di dalam tembawang (Peluso, 2005). Hutan tembawang banyak ditumbuhi berbagai jenis pohon penghasil buah seperti durian, nangka, langsat, mangga, duku, rambutan, cempedak, dan buah-buahan hutan yang dapat dimakan. (Darusman, 2001) Semua jenis pohon yang ada di tembawang ini selain merupakan hasil penanaman masyarakat saat mereka akan meninggalkan ladangnya untuk pindah ke tempat yang lebih subur, juga terdapat pohon pohon tua yang tidak ikut tertebang ketika berladang.

Penelitian mengenai buah yang dapat dimakan (edibel) di berbagai kawasan hutan Kalimantan Barat telah banyak dilakukan. Natalis (2011) di Hutan Peringek Desa Karangan Kabupaten Landak mendata 29 spesies buah edibel. Heronimus (2010) penelitiannya menemukan 49 spesies di Desa Jangkang dan 52 spesies di Desa Semobat di Kabupaten Sanggau Kapuas diantaranya Baccaurea lanseolata (rambai), Ficus carica L. (ara), dan Pometia pinnata (matoa).

Tembawang Desa Tirta Kencana memiliki berbagai jenis buah-buahan edibel. Masyarakat Desa Tirta Kencana ini pun sebagian masih memanfaatkan jenis buah-buahan hutan untuk 
dikonsumsi atau dimakan sebagai kebutuhan sehari-hari. Informasi mengenai jenis-jenis buahbuahan yang dimanfaatkan di hutan tersebut belum diketahui, sehingga perlu dilakukan penelitian ini.

\section{BAHAN DAN METODE}

\section{Waktu dan Tempat}

Penelitian ini telah dilaksanakan selama dua bulan pada bulan April 2019 sampai Mei 2019 yang meliputi persiapan, wawancara responden, pengambilan sampel tumbuhan dan pengolahan data. Pengambilan sampel tumbuhan buah edibel dilaksanakan di hutan tembawang Desa Tirta Kencana Kecamatan Bengkayang Kabupaten Bengkayang. Pengolahan data dilakukan di Laboratorium Biologi Fakultas Matematika dan Ilmu Pengetahuan Alam Universitas Tanjungpura Pontianak.

\section{Deskripsi Lokasi}

Desa Tirta Kencana adalah salah satu desa yang ada di Kecamatan Bengkayang. Desa ini dapat ditempuh dengan kendaraan roda dua dan roda empat dari Kabupaten Bengkayang. Jarak tempuh dari kota kecamatan kurang lebih $5 \mathrm{~km}$ dengan waktu tempuh 20 menit. Desa Tirtakencana memiliki luasan $4311 \mathrm{Ha}$ (Anonim, 2015).

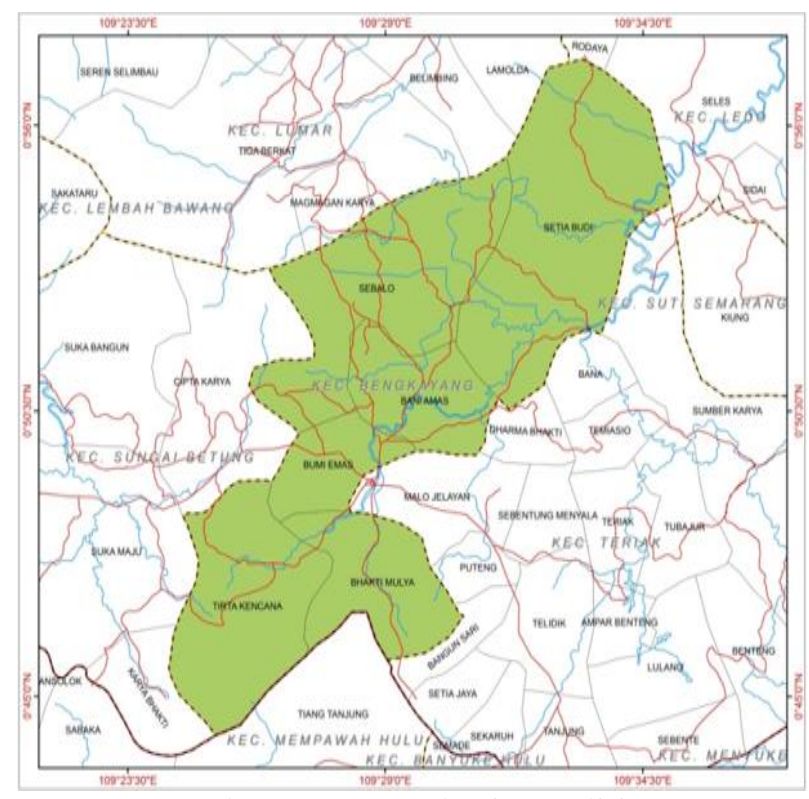

Gambar 1. Peta Lokasi Penelitian.

\section{Alat dan Bahan}

Alat yang digunakan dalam penelitian adalah perekam suara, benang jahit, botol spesimen, buku identifikasi, double tip, GPS (Global Positioning System), gunting, isolasi, jarum, kamera digital, plastik packing, kayu penjepit, kardus, kertas label, kertas karton, koran bekas, pisau, parang, sprayer, etiket gantung, dan tali rafia.

Bahan yang digunakan adalah buah edibel yang ada di kawasan hutan tembawang Desa Tirta Kencana Kecamatan Bengkayang Kabupaten Bengkayang. Alkohol 70\% digunakan untuk pembuatan herbarium kering dan formalin $4 \%$ di gunakan untuk pembuatan herbarium basah.

\section{Prosedur Kerja}

Penentuan responden dilakukan dengan metode purposive sampling. Pemilihan responden didasarkan pertimbangan kesesuaian dengan tujuan kajian. Responden dipilih dengan sengaja dan berdasarkan pengetahuan responden serta kualitas informasi yang dapat diberikan (Tongco, 2007).

Pengambilan sampel tumbuhan buah edibel di lapangan dilakukan dengan metode survei lapangan berdasarkan informasi yang diperoleh dari responden. Setiap tumbuhan yang diperoleh difoto, dicatat nama lokal, nama ilmiahnya dan lokasi ditemukan.

Proses identifikasi dilakukan langsung di lapangan, apabila terdapat jenis buah edibel yang tidak diketahui secara lengkap maka akan di lakukan identifikasi lebih lanjut di Laboratorium Biologi Fakultas Matematika dan Ilmu Pengetahuan Alam Universitas Tanjungpura Pontianak. Proses identifikasi buah edibel didasarkan pada karakteristik morfologi organ tumbuhan yaitu akar, batang, daun, bunga, buah, dan biji.

\section{HASIL DAN PEMBAHASAN}

Hasil penelitian buah edibel di hutan tembawang Suku Dayak Bakati Desa Tirta Kencana Kecamatan Bengkayang Kabupaten Bengkayang, diperoleh 21 jenis buah edibel yang termasuk dalam 14 famili. (Tabel 1). Buah edibel yang paling banyak dikonsumsi oleh masyarakat adalah famili dari Moraceae sebanyak 5 jenis. 
Tabel 1 Jenis-jenis Buah Edibel yang terdapat di Hutan Tembawang Suku Dayak Bakati Desa Tirta Kencana Kecamatan Bengkayang Kabupaten Bengkayang.

\begin{tabular}{|c|c|c|c|c|}
\hline No & famili & Nama ilmiah & Nama indonesia & Nama daerah \\
\hline 1 & Moraceae & Ficus carica $\mathrm{L}$. & Ara & Ara \\
\hline 2 & Moraceae & Artocarpus integra Merr. & Nangka & Sejampo \\
\hline 3 & Moraceae & Artocarpus anisophyllus Var. & Mentawa & Mentawa \\
\hline 4 & Moraceae & Artocarpus chempeden Lorr. & Cempedak & nangka \\
\hline 5 & Moraceae & Artocarpus rigidus $\mathrm{BI}$. & Peluntan & Perunta't \\
\hline 6 & Euphorbiceae & Antidesma Bunicus L. & Buni & Anyham \\
\hline 7 & Euphorbiceae & Bacaurea graffithri Hook.f & Tampoi & Tampi \\
\hline 8 & Euphorbiaceae & Bacaurea motleyana Merr. & Rambai & Ulap \\
\hline 9 & Anacardiceae & Mangifera foetida $\mathrm{L}$. & Asam bacang & Asum bacang \\
\hline 10 & Anacardiceae & Mangifera pajang Kosterm. & Asam mawang & Asum maow \\
\hline 11 & Solanaceae & Physalis minima $\mathrm{L}$. & Ciplukan & Tangkukop \\
\hline 12 & Pasifloraceae & Pasiflora foetida $\mathrm{L}$. & Permot & Kamban'g \\
\hline 13 & Melastomaceae & Melastoma Polyanthum BI. & Cengkodok & Takan'g \\
\hline 14 & Arecaceae & Salacca affinis Griff & Salak hutan & Angkan'g \\
\hline 15 & Meliaceae & Lansium domesticum Correa. & Langsat & Sarikan’t \\
\hline 16 & Fegaceae & Castanea argentea BL. & Berangan & Banghan \\
\hline 17 & Bombaceae & Durio zibethinus Murr. & Durian & Dihan't \\
\hline 18 & Caesalpinaceae & Dialium indum $\mathrm{L}$. & Keranji & Keranyi \\
\hline 19 & Burseraceae & Canarium odontophylum Miq. & Sengkuhum & Sengkuhum \\
\hline 20 & Sapindaceae & Nephelium mutabile BI. & Rambutan hutan & Sibo \\
\hline 21 & Musaceae & Musa paradisiaca L. & Pisang hutan & Pisan'g \\
\hline
\end{tabular}

Berdasarkan hasil wawancara terhadap responden masyarakat Desa Tirta Kencana, bagian buah yang

dapat dikonsumsi adalah daging buah, biji buah, kulit buah (Tabel 2).

Tabel 2 Buah yang Dikonsumsi Oleh Masyarakat Suku Dayak Bakati Desa Tirta Kencana Kecamatan Bengkayang Kabupaten Bengkayang

\begin{tabular}{|c|c|c|c|c|c|}
\hline No & Nama ilmiah & Nama Indonesia & Daging & Biji & Kulit \\
\hline 1 & Moreacae & Ara & $\sqrt{ }$ & - & - \\
\hline 2 & Moreacae & Nangka & $\sqrt{ }$ & $\sqrt{ }$ & - \\
\hline 3 & Moreacae & Mentawa & $\sqrt{ }$ & $\sqrt{ }$ & - \\
\hline 4 & Moreacae & Cempedak & $\sqrt{ }$ & $\sqrt{ }$ & - \\
\hline 5 & Moreacae & Peluntan & $\sqrt{ }$ & $\sqrt{ }$ & - \\
\hline 6 & Euphorbiceae & Buni & $\sqrt{ }$ & - & - \\
\hline 7 & Euphorbiceae & Tampoi & $\sqrt{ }$ & $\sqrt{ }$ & - \\
\hline 8 & Euphorbiceae & Rambai & $\sqrt{ }$ & $\sqrt{ }$ & $\sqrt{ }$ \\
\hline 9 & Anacardiceae & Asam bacang & $\sqrt{ }$ & - & - \\
\hline 10 & Anacardiceae & Asam mawang & $\sqrt{ }$ & - & - \\
\hline 11 & Solanaceae & Ciplukan & $\sqrt{ }$ & - & - \\
\hline 12 & Pasifloraceae & Permot & $\sqrt{ }$ & - & - \\
\hline 13 & Melastomaceae & Cengkodok & $\sqrt{ }$ & - & - \\
\hline 14 & Arecaceae & Salak hutan & $\sqrt{ }$ & - & - \\
\hline 15 & Meliaceae & Langsat & $\sqrt{ }$ & - & - \\
\hline 16 & Fegaceae & Berangan & $\sqrt{ }$ & $\sqrt{ }$ & - \\
\hline 17 & Bombaceae & Durian & $\sqrt{ }$ & - & - \\
\hline 18 & Caesalpinaceae & Keranji & $\sqrt{ }$ & - & - \\
\hline 19 & Burseraceae & Sengkuhum & $\sqrt{ }$ & $\sqrt{ }$ & $\sqrt{ }$ \\
\hline 20 & Sapindaceae & Rambutan hutan & $\sqrt{ }$ & - & - \\
\hline 21 & Musaceae & Pisang hutan & $\sqrt{ }$ & - & - \\
\hline \multicolumn{3}{|c|}{ Jumlah } & 21 & 8 & 2 \\
\hline
\end{tabular}

Keterangan : $\sqrt{ }$ ( bagian yang dikonsumsi ) - ( bagian yang tidak dikonsumsi ) 
Masyarakat Suku Dayak Bakati di Desa Tirta Kencana Kecamatan Bengkayang memiliki cara dalam pengolahan atau pemanfaatan buah edibel dan masih terbilang sangat sederhana (Tabel 3). Sebagian besar dari buah edibel dimakan langsung tanpa melalui pengolahan terlebih dahulu.

Tabel 3 Dayak Bakati Desa Tirta Kencana Kecamatan Bengkayang Kabupaten Bengkayang Cara Pemanfaatan Buah Edibel Oleh Masyarakat Suku

\begin{tabular}{|c|c|c|c|}
\hline No & Jenis buah & Cara pemanfaatan & Rasa buah \\
\hline 1 & Artocarpus chempeden Lorr. & Dijadikan sayur, dimakan langsung & manis \\
\hline 2 & Artocarpus integra Merr. & Dijadikan sayur, dimakan langsung & Manis \\
\hline 3 & Artocarpus anisophyllus Var. & Dijadikan sayur, dimakan langsung & Manis \\
\hline 4 & Artocarpus rigidus $\mathrm{BI}$. & $\begin{array}{l}\text { Dijadikan sayur, dimakan langsung, bijinya } \\
\text { disangrai }\end{array}$ & Manis \\
\hline 5 & Ficus carica L. & Dimakan langsung & Sedikit asam \\
\hline 6 & Antidesma bunicus L. & Dimakan langsung, & Asam, manis \\
\hline 7 & Bacaurea graffithri Hook.f & Dimakan langsung & Asam, manis \\
\hline 8 & Bacaurea motleyana Merr. & Dimakan langsung, dijadikan sayur,bumbu masak & Asam, manis \\
\hline 9 & Mangifera foetida $\mathrm{L}$ & Dimakan langsung & Asam, manis \\
\hline 10 & Mangifera pajang Kosterm. & Dimakan langsung & Asam, manis \\
\hline 11 & Physalis minima $\mathrm{L}$. & Dimakan langsung & Asam, manis \\
\hline 12 & Durio zibethinus Murr. & $\begin{array}{l}\text { Dimakan langsung, dijadikan dodol, dijadikan } \\
\text { sayur }\end{array}$ & manis \\
\hline 13 & Lansium domesticum Correa. & Dimakan langsung & Asam, manis \\
\hline 14 & Pasiflora foetida $\mathrm{L}$. & Dimakan langsung & Asam \\
\hline 15 & Melastoma polyanthum $\mathrm{BI}$. & Dimakan langsung & Kelat, manis \\
\hline 16 & Salacca affinis Griff. & Dimakan langsung & Kelat, manis \\
\hline 17 & Dialium indum $\mathrm{L}$. & Dimakan langsung & Asam \\
\hline 18 & Nephelium mutabile BI. & Dimakan langsung & Asam, manis \\
\hline 19 & Musa paradisiaca $\mathrm{L}$. & Dimakan langsung & Manis \\
\hline 20 & Canarium odontophylum Miq. & Dimakan langsung, dijadikan sayuran & Tawar, manis \\
\hline 21 & Castanea argentea BL. & Direbus & Sedikit manis \\
\hline
\end{tabular}

\section{Pembahasan}

Jenis-jenis buah edibel yang dikonsumsi oleh masyarakat suku Dayak Bakati Desa Tirta Kencana Kecamatan Bengkayang Kabupaten Bengkayang diketahui sebanyak 21 spesies. Buah edibel yang paling banyak dikonsumsi yaitu buah dari famili Moraceae sebanyak 5 spesies.

Banyaknya jenis tumbuhan dari famili Moraceae dikonsumsi dikarenakan tumbuhan tersebut selain sering dikonsumsi sebagai buah, juga dapat dikonsumsi dalam bentuk sayur contohnya seperti buah nangka (Artocarpus integra Merr), peluntan (Artocarpus rigidus BI). Menurut (Nuswamarhaeni et al., 1989), rasa buah yang manis cenderung akan dimanfaatkan relatif lebih banyak oleh masyarakat.

Hasil penelitian yang dilakukan oleh Kurniawati, (2015) di Desa Setia Jaya Kecamatan Teriak Kabupaten Bengkayang menemukan 25 spesies buah edibel. Sedangkan hasil penelitian Marin (2011) di Desa Sibau Hulu Kecamatan Putusibau Utara, Kabupaten Kapuas Hulu menemukan tum- buhan buah edibel sebanyak 35 spesies. Dari hasil penelitian tersebut lebih banyak jika dibandingkan dengan Desa Tirta Kencana, dikarenakan adanya faktor salah satunya penebangan pohon oleh penduduk setempat dan adanya penduduk setempat tidak mengetahui banyak adanya tumbuhan buah edibel yang bisa dikonsumsi. Faktor lain yang mempengaruhi adalah terjadinya alih fungsi kawasan hutan tembawang di Desa Tirta Kencana menjadi area kebun karet. Ada juga sebagian penduduk desa menjadikan lahan hutan tersebut tepatnya di bawah kaki hutan untuk tambang pencarian emas (dompeng).

Berdasarkan data yang diperoleh bagian buah paling banyak dikonsumsi adalah bagian daging buah yaitu 21 spesies buah edibel, sedangkan bagian buah yang paling sedikit adalah kulit misalnya buah sengkuhum (Canarium odontophylum Miq.) dan Rambai (Bacaurea motleyana Merr). Dalam penelitian Marin (2011), bahwa di Desa Sibau Hulu Kecamatan Putusibau Utara Kabupaten Kapuas Hulu dapat mengkonsunsi bagian kulit buah dari Ficus carica 
L. (ara) sedangkan masyarakat Desa Tirta Kencana, kulit buah dari jenis itu tidak dapat dikonsumsi. Daging buah memiliki rasa yang manis dan ada juga rasa asam contohnya buah buni (Antidesma bunicus L). Tekstur tersebut tidak keras dan pada umumnya dapat dimakan secara langsung tanpa melaui pengolahan terlebih dahulu.

Cara mengonsumsi buah edibel oleh masyarakat Desa Tirta Kencana masih sangat tergolong sederhana yaitu dimakan langsung. Buah-buahan mengandung air yang dapat menghilangkan rasa haus dan lapar pada waktu masyarakat melakukan aktifitas. Adapun buah yang dapat dimakan secara langsung pada saat masyarakat Desa Tirta Kencana melakukan aktifitas di hutan yaitu Ficus carica L. (ara), Physalis minima L.(ciplukan), Passiflora foetida L. (permot), Melastoma polyanthum BI. (Cengkodok), Salacca affinis Griff. (Salak hutan), Antidesma bunicus L. (Buni), Bacaurea graffithri Hook.f (tampoi), Bacaurea motleyana Merr. (rambai), Lansium domesticum Correa. (langsat), Durio zibethinus Murr. (durian), Nephelium mutabile BI. (rambutan hutan), Musa paradisiaca L. (pisang hutan).

Buah yang dimakan secara langsung biasanya memiliki rasa yang manis, masam dan tekstur yang lembut. Pemanfaatan tumbuhan buah edibel oleh masyarakat setempat masih kurang karena oleh kualitas buah dan rasa yang manis. Rasa buah yang manis dan enak cenderung akan dimanfaatkan atau dikonsumsi lebih banyak oleh masyarakat.

Hasil wawancara terhadap responden diketahui cara pemanfaatan buah yang dilakukan oleh masyarakat masih sangat sederhana (Tabel 3). Cara mengkonsumsi buah ini dilakukan berdasarkan pengalaman dari orang tua sebelumnya yang diterapkan dalam kehidupan sehari-hari dan tidak mengalami perubahan.

Menurut (Suharjo et al., 1986) pola kebudayaan mempengaruhi orang dalam memperoleh makanan, mengolahnya yang kemudian berkembang menjadi makanan yang cocok. Fermentasi digunakan oleh masyarakat Suku Dayak Bakati Desa Tirta Kencana untuk mengawetkan buah agar dapat disimpan dalam waktu yang lama. Teknik fermentasi yang dilakukan oleh masyarakat adalah dengan menaburkan garam kemudian dimasukkan kedalam wadah tertutup, selanjutnya dibiarkan beberapa hari sampai garam benar benar larut.
Contoh buah yang dapat difermentasikan adalah durian (Durio zibethinus Murr).

\section{DAFTAR PUSTAKA}

Anonim. 2015 "Profil Desa Tirtakencana". Kantor Camat Bengkayang. Kabupaten Bengkayang

Darusman, D. 2001. Resilieinsi Kehutanan Masyarakat Di Indonesia. Debut Press. Yogyakarta.

De Foresta H, Kusworo A, Klichon G, Djatmiko WA. 2000. Ketika Kebun Berupa Hutan Agroforest Khas Indosnesia- Sumbangan Masyarakat Bagi Pembangunan Berkelanjutan. Jakarta(ID):SMT Grafika Desa Putera.

Heronimus, 2010, Inventarisasi Tumbuhan Buah Edibel di Tembawang Desa Jangkang dan Semubat Kecamatan Jangkang Kabupaten Sanggau, Skripsi,Fakultas Pertanian, Universitas Tanjungpura, Pontianak

Marin, B. 2011, Studi Keanekaragaman Buah-buahan Liar Edibel di Desa Sibau Hulu Kecamatan Putusibau Utara Kabupaten Kapuas Hulu, Skripsi, Fakultas Pertanian, Universitas Tanjungpura, Pontianak

Natalis, R, 2011, Inventarisasi Tumbuhan Buah-Buahan Edibel di Hutan Peringek Desa Karangan Kecamatan Mempawah Hulu Kabupaten Landak, Skripsi, Fakultas Pertanian, Universitas Tanjungpura, Pontianak

Nuswarmarhaeni, S, Diah, P dan Endang, P. 1989. Mengenal Buah Unggul Indonesia. Penebar Swadaya, Jakarta.

Peluso, NL. 2005. Seeing Property In Land Use: Local Territorializations In West Kalimantan, Indonesia. Danish Journal Of Geography. 105(1):1-15.

Sardana A, Hernawati J, Dharma MGGY, Nugroho AE, Aliyah N. 2011. Potret Provinsi Kalimantan Barat. Kementrian Kehutanan Direktorat Jendral Planologi Kehutanan Balai Pemantapan Kawasan Hutan Wilayah III Pontianak(ID): Pontianak

Suharjo, Laura, JH, Brady, JD \& Judy, AD. 1986, Pangan, Gizi dan Pertanian, Universitas Indonesia Press.

Tongco, MDC, 2007, 'Purposive Sampling as a Tool for Informant Selection', Etnobotanical Research \& Applications, Vol. 5, hal. 145-158, diakses 20 Oktober 2018, http://journal.purposive.sampling.com 
Protobiont (2019) Vol. 8 (3) : 95 - 100

Tri Esti Kurniawati. 2015. Kajian Pemanfaatan Buah Edibel Suku Dayak Banyadu DiHutan Tembawang Desa Setia Jaya Kecamatan Teriak Kabupaten Bengkayang.,Protobiont. 4(1): 10-16. 